\title{
A retrospective drug use evaluation of cabergoline for lactation inhibition at a tertiary care teaching hospital in Qatar
}

This article was published in the following Dove Press journal:

Therapeutics and Clinical Risk Management

9 February 2016

Number of times this article has been viewed

\author{
Doua AISaad' \\ Samah EISalem' \\ Palli Valapila Abdulrouf' \\ Binny Thomas ${ }^{1,2}$ \\ Tayseer Alsaad ${ }^{3}$ \\ Afif Ahmed' \\ Moza AlHail ${ }^{4}$ \\ 'Department of Pharmacy, Women's \\ Hospital, Hamad Medical Corporation, \\ Doha, Qatar; ${ }^{2}$ Department of \\ Pharmacy and Life Sciences, Robert \\ Gordon University, Aberdeen, UK; \\ ${ }^{3}$ Department of Pediatrics, Hamad \\ General Hospital, ${ }^{4} \mathrm{Clinical}$ Support \\ Service Unit, Hamad Medical \\ Corporation, Doha, Qatar
}

Background: Breastfeeding is considered as gold standard for infant nutrition and should be interrupted only when a compelling indication exists. Certain medical conditions such as abortion, stillbirth, HIV infection, or infant galactosemia and certain medications such as chemotherapy necessitate lactation inhibition to protect the health of mother and infant. Drug use evaluation (DUE) studies are done to explore the current practice in a setting and help to identify areas in which further information and education may be needed by clinicians.

Objective: The aim of this study was to conduct a DUE of cabergoline to assess indications for lactation inhibition, dosage regimen, and its safety.

Method: A retrospective cross-sectional DUE study was conducted over a period of 4 months from September 1, 2013, till December 31, 2013, at the Women's Hospital, Qatar. All cabergoline prescriptions written for lactation inhibition within 10 days of delivery or abortion were included in the study. A descriptive data analysis was undertaken.

Results: Of the 85 patients included, stillbirth (50.6\%) was considered as the main reason for lactation inhibition, followed by abortion (27.1\%) and neonatal death (12.9\%). The remaining $9.4 \%$ of the patients had live baby, and the majority of them were prescribed cabergoline for lactation inhibition because their maternal medical conditions required the use of drugs with insufficient safety data $(n=6)$. Seventy-four percent of patients received cabergoline at accurate time and dose. However, 14\% of the patients had preexisting hypertensive disorder and $58.3 \%$ of them were diagnosed as uncontrolled hypertension.

Conclusion: The current DUE study found that cabergoline was mainly used to inhibit lactation for patients with stillbirth, abortion, and neonatal death. In mothers who use medications for other medical conditions, benefits and risks of breastfeeding should be carefully balanced before prescribing cabergoline. Current prescribing pattern can be further enhanced through informing health care providers regarding appropriate cabergoline dosage regimen and its safety in patients with uncontrolled hypertension.

Keywords: lactation inhibition, cabergoline, drug use evaluation, breastfeeding inhibition

\section{Introduction}

Human milk is the normative standard for infant feeding and nutrition. It provides short- and long-term nutritional, cognitive, emotional, and immunologic advantages. Medical contraindications to breastfeeding are few. These include infant galactosemia or mother's HIV infection, untreated and active tuberculosis, or use of some chemotherapy agents. Furthermore, some mothers avoid breastfeeding on personal or social grounds. Regardless of the reason for not breastfeeding, this decision can be associated with complications including milk secretion, breast pain, engorgement, or mastitis. $^{1-7}$
Correspondence: Doua AlSaad

Department of Clinical Pharmacy,

Women's Hospital, Hamad Medical

Corporation, PO Box 3050, Doha, Qatar

Tel +97444393340

Fax +974 44393867

Email alsaad.doua@gmail.com 
Various approaches are used to suppress lactation in women. Severe breast pain can be encountered in women who do not breastfeed and use analgesics or use nonpharmacological approaches to suppress lactation such as breast binder or ice packs. ${ }^{8}$ Furthermore, the use of pharmacological interventions such as estrogens alone, estrogen-androgen combination, pyridoxine, and dopamine agonists have been evaluated for efficacy in milk suppression and have shown variable results. ${ }^{5}$

Cabergoline is a dopamine agonist used to suppress lactation despite the lack of approval from the United States Food and Drug Administration for this indication. It exerts its effect through the inhibition of prolactin release from the anterior pituitary gland. Compared to bromocriptine, the older dopamine agonist, cabergoline is better tolerated with significantly less rebound breast activity and adverse effects and with more simple administration schedule. ${ }^{9,10}$

A number of studies have been conducted to examine the dose-dependent effect of cabergoline. ${ }^{11-14} \mathrm{~A}$ range of oral doses between $0.4 \mathrm{mg}$ and $1 \mathrm{mg}$ was used, and the most effective dose for long-term suppression of lactation was found to be $1 \mathrm{mg} .{ }^{15}$ Accordingly, a single dose of $1 \mathrm{mg}$ during the first 24-27 hours postpartum is recommended for lactation inhibition, ${ }^{10,16}$ while a dose of $0.25 \mathrm{mg}$ every 12 hours for four doses is used for suppression of established lactation. ${ }^{16}$

Drug use evaluation (DUE) is a process of ongoing, systematic, criteria-based evaluation of drug use with the aim of ensuring that medications are used appropriately at the individual patient level. ${ }^{17}$ DUE studies are a powerful tool to explore the pattern of prescribing medications, promote optimal medication therapy, and prevent medication-related problems. In addition, DUE studies help to identify areas in which further education or information may be needed by health care providers. ${ }^{17}$

A valid indication is necessary for the use of cabergoline to inhibit lactation in nursing mothers. Physicians must be aware of the dose, indication, and frequency to prescribe cabergoline in nursing mothers. They also should review maternal medical conditions to ensure its safety. Therefore, we aimed to conduct a DUE of cabergoline to assess indications for lactation inhibition, dosage regimen, and its safety.

\section{Method}

\section{Study setting and period}

This DUE study was conducted at the Women's Hospital, Qatar. This tertiary care facility has 234 beds including antenatal, postnatal, and high dependency units, an outpatient department followed by an emergency room, 16 labor rooms, and three operating theaters, as well as a level-3 neonatal intensive care unit. All cabergoline prescriptions for lactation inhibition written over a 4-month period between September 1, 2013, and December 31, 2013, were used in the study.

\section{Study design}

This retrospective cross-sectional study was conducted to evaluate the use of cabergoline in lactation inhibition. A literature review along with World Health Organization guidelines on conducting DUE studies was utilized for the DUE criteria selection. ${ }^{17}$ The primary outcomes for the study were

1. Identify and assess indications for lactation inhibition.

2. Evaluate the appropriateness of cabergoline dosage regimen.

3. Evaluate the safe use of cabergoline in patients with existing medical comorbidities.

\section{Eligibility criteria}

Women who received a cabergoline prescription for lactation inhibition within 10 days of delivery or abortion were included in the study.

\section{Data collection}

A standardized data collection tool was developed utilizing the selected DUE criteria. Variables were designated to measure the prespecified outcomes. The tool was validated through piloting it on ten randomly selected files.

\section{Outcome measures}

The Centers of Disease Control and Prevention and American Academy of Pediatrics resources were utilized to identify the medical conditions that necessitate lactation inhibition. ${ }^{18,19}$ Drugs in Pregnancy and Lactation book and Drugs and Lactation Database (LactMed) by the US National Library of Medicine were used to identify the safety of medications with breastfeeding. ${ }^{15,20}$ A single dose of $1 \mathrm{mg}$ of cabergoline within the first 24-27 hours of delivery/abortion is the recommended regimen for lactation inhibition. ${ }^{10,16}$ The main safety concerns for the use of cabergoline that were evaluated in this study were preexisting uncontrolled hypertension at the time of cabergoline administration and allergy with ergot alkaloid since the use of cabergoline in these populations could cause significant risk to patients.

\section{Definitions}

In this study, lactation inhibition refers to the prevention of milk formation within the first 27 hours postpartum before the mother starts breastfeeding, whereas lactation suppression pertains to suppression of established lactation. There is 
no clear definition and duration for controlled hypertension before cabergoline administration. So we defined controlled hypertension as having systolic blood pressure $<150 \mathrm{mmHg}$ and diastolic blood pressure $<100 \mathrm{mmHg}^{21}$ within the previous 24 hours before prescribing cabergoline without intravenous antihypertensive medications to control the blood pressure.

\section{Data processing and analysis}

Data collection was done using patients' medical records, and the collected data were manually sorted and categorized. A descriptive data analysis was carried out and evaluated against the preset criteria.

\section{Ethical consideration}

Waiver of informed consent and ethical approval were obtained from the Medical Research Center, Hamad Medical Corporation (approval number 13393/13).

\section{Results}

A total of 232 patients were prescribed cabergoline, of which 85 patients were included in this study (Figure 1). Demographic characteristics of patients are shown in Table 1. Thirty-one percent of the patients were Qataris, and the majority of the patients had a singleton pregnancy $(90.6 \%)$.

\section{Indications for lactation inhibition}

Stillbirth was found to be the main reason to inhibit lactation (50.6\%), followed by abortion (27.1\%) and neonatal death
(12.9\%). Only $9.4 \%$ of the patients who received cabergoline for lactation inhibition had live baby (Table 2).

\section{Appropriateness of indications for lactation inhibition}

Following abortion, only one patient received cabergoline at gestational age $<16$ weeks as patient requested, whereas all the other patients received cabergoline at a higher gestational age.

In patients with live baby, no infant or maternal medical conditions that required lactation inhibition were encountered. One of the patients with severely inverted nipples requested cabergoline to suppress her lactation. Six patients who used medications for postkidney transplant, depression, epilepsy, and cardiomyopathy did not breastfeed their babies. All these patients were using combinations of medications (Table 2). Only one patient requested lactation inhibition with no clear reason.

\section{Cabergoline dosage}

The majority of the patients were prescribed cabergoline during hospital admission ( $83.5 \%$ ), while the rest were prescribed cabergoline at discharge as home medication. Cabergoline was prescribed within the first 27 hours of delivery or abortion in $>80 \%$ of the patients and was prescribed as a single dose of $1 \mathrm{mg}$ in $71.8 \%$ of the patients. Appropriate prescribing pattern of both timing and dose was found in $74.1 \%$ of the patients (Table 3 ). It was noted that $50 \%$ of the patients with live baby received cabergoline after 27 hours of delivery.



Figure I Patients selection for inclusion. 
Table I Demographic characteristics

\begin{tabular}{|c|c|}
\hline Variables & n (\%) \\
\hline \multicolumn{2}{|l|}{ Age (years) } \\
\hline$<20$ & I (I.2) \\
\hline $20-29$ & $35(4 \mid .2)$ \\
\hline $30-39$ & $38(44.7)$ \\
\hline$>40$ & II (12.9) \\
\hline \multicolumn{2}{|l|}{ Nationality } \\
\hline Qatari & $27(3 \mid .8)$ \\
\hline Gulf Cooperation Council countries & $7(8.2)$ \\
\hline Egyptian & $7(8.2)$ \\
\hline Indian & $6(7.1)$ \\
\hline Filipino & $6(7.1)$ \\
\hline Others ${ }^{\mathrm{a}}$ & $32(37.6)$ \\
\hline \multicolumn{2}{|l|}{ Gravidity } \\
\hline I & $24(28.2)$ \\
\hline$\geq 2$ & $59(69.4)$ \\
\hline \multicolumn{2}{|l|}{ Parity ${ }^{b}$} \\
\hline 0 & $27(31.8)$ \\
\hline I & $24(28.2)$ \\
\hline$\geq 2$ & 32 (37.6) \\
\hline \multicolumn{2}{|l|}{ Number of pregnancies } \\
\hline Singleton & $77(90.6)$ \\
\hline Twins & $7(8.2)$ \\
\hline Triplets & I (I.2) \\
\hline \multicolumn{2}{|l|}{ Allergy } \\
\hline Ergot alkaloid & 0 \\
\hline
\end{tabular}

Notes: ${ }^{a}$ Others (n): Yemeni (5), Pakistani (5), Sudanese (4), Jordanian (4), Iranian (2), Palestinian (2), Lebanese (2), Bangladeshi (2), Indonesian (I), Moroccan (I), Nepalese (I), Mauritian (I), Syrian (I), and Senegalese (I). ${ }^{b}$ Data are missed for two patients.

\section{Safety of administration}

Fourteen percent of the patients had hypertensive disorders during current pregnancy. Fifty-eight percent of these patients had uncontrolled blood pressure 24 hours prior to prescribing cabergoline (Figure 2). None of the

Table 2 Indication for lactation inhibition

\begin{tabular}{lll}
\hline Indication & $\mathbf{n}(\%)$ & Comments \\
\hline $\begin{array}{l}\text { Abortion } \\
<16 \text { weeks }\end{array}$ & $23(27.1)$ & \\
& 1 & $\begin{array}{l}\text { At 7 weeks, patient } \\
\text { request }\end{array}$ \\
16-20 weeks & & \\
$21-23$ weeks & 6 & \\
Stillbirth & 16 & \\
Neonatal death & $43(50.6)$ & \\
Live infant & $11(12.9)$ & \\
$\quad$ Infant medical condition & $8(9.4)$ & \\
Maternal structural problems & 0 & Severely inverted \\
& 1 & nipples \\
Maternal infection/medical condition & 0 & \\
Medication/chemicals use & & \\
Others & 6 & Unclear reason, \\
& 1 & patient request \\
\hline
\end{tabular}

Notes: aedications used by each patient: Patient I: prednisolone $5 \mathrm{mg}$ daily, rosuvastatin $10 \mathrm{mg}$ daily, tacrolimus $4 \mathrm{mg}$ am and $3 \mathrm{mg}$ pm, mycophenolate I g BID, kidney transplant. Patient 2: azathioprine $75 \mathrm{mg}$ daily, tacrolimus $3 \mathrm{mg}$ BID, prednisolone $5 \mathrm{mg}$ daily, kidney transplant. Patient 3: amitriptyline $75 \mathrm{mg}$ daily, fluphenazine $0.5 \mathrm{mg}$ daily, nortriptyline $10 \mathrm{mg}$ daily, depression. Patient 4: amitriptyline $25 \mathrm{mg}$ daily, fluoxetine 20 daily, depression. Patient 5: oxcarbazepine $300 \mathrm{mg}$ BID, levetiracetam $500 \mathrm{mg}$ TID, epilepsy. Patient 6: carvedilol 12.5 mg BID, furosemide 40 daily, cardiomyopathy. Abbreviations: BID, twice daily; TID, three times daily.
Table 3 Dosage regimen of cabergoline

\begin{tabular}{|c|c|}
\hline Cabergoline prescription & n (\%) \\
\hline \multicolumn{2}{|l|}{ Cabergoline prescription written for } \\
\hline In-patient administration & $71(83.5)$ \\
\hline Home administration & $14(16.5)$ \\
\hline \multicolumn{2}{|c|}{ Timing between abortion/delivery and writing prescription } \\
\hline$\leq 27$ hours & $71(83.5)$ \\
\hline$>27$ hours & $14(16.5)$ \\
\hline Abortion & 4 \\
\hline Stillbirth & 3 \\
\hline Neonatal death & 3 \\
\hline Live baby & 4 \\
\hline \multicolumn{2}{|l|}{ Dosing } \\
\hline I mg single dose & $6 I(7 \mid .8)$ \\
\hline $0.25 \mathrm{mg}$ twice daily for four doses & $21(24.7)$ \\
\hline Others $\mathrm{s}^{\mathrm{a}}$ & $3(3.5)$ \\
\hline Proper timing and dosing of cabergoline & $63(74.1)$ \\
\hline \multicolumn{2}{|c|}{ Note: aOthers (n): I mg for two doses I week apart (I), 0.5 mg single dose (2). } \\
\hline
\end{tabular}

\section{Discussion}

This DUE study explores the current clinical practice and provides an evidence for the use of cabergoline in lactation inhibition with an emphasis on the indications and safety. To the best of our knowledge, no DUE studies on cabergoline use for lactation inhibition were published elsewhere.

Lactogenesis starts at $\sim 16$ weeks of gestation. ${ }^{22,23}$ Most of the patients received cabergoline at late gestational ages. Only $9.4 \%$ of the patients who received cabergoline had live baby. The main reason for that was the use of other medications by the mothers for their existing maternal comorbidities. Not all the received medications contraindicate breastfeeding, ${ }^{15,20}$ but may be the use of combinations of these medications led to the decision of lactation inhibition.

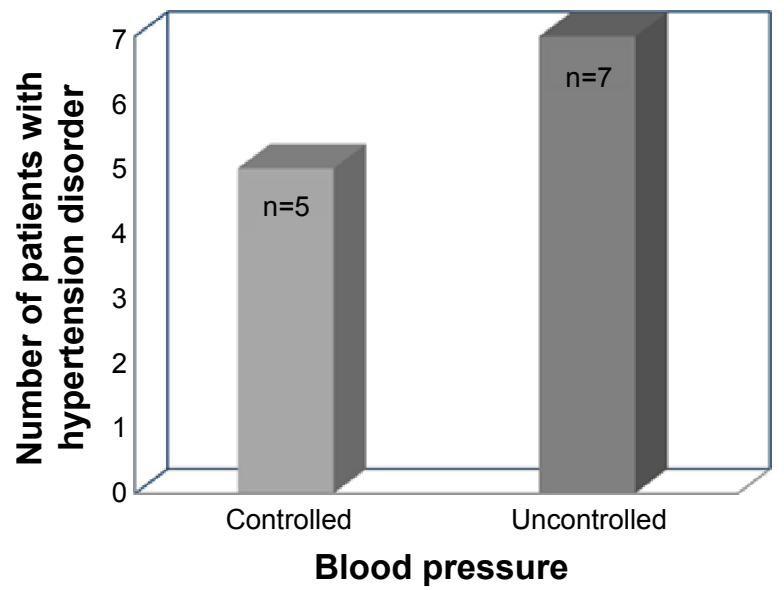

Figure 2 Cabergoline safety.

Note: Total patients $n=85$, patients with blood pressure disorder $n=12$. 
Generally, for many of the medications that possess a low risk to the nursing baby, breastfeeding can be continued with close monitoring of the baby and with proper timing between medication administration and breastfeeding if applicable or a safer alternative can be used when appropriate.

Many studies assessed the prolactin inhibitory effect of different cabergoline doses, and the $1 \mathrm{mg}$ single dose was shown to be the most effective dose. ${ }^{13,14}$ In our study, the $1 \mathrm{mg}$ single dose was prescribed in $71.8 \%$ of the patients. Cabergoline administration should take place within the first 24-27 hours of delivery. ${ }^{10,16}$ Delay beyond this time period was noted in $50 \%$ of the patients with live baby, which might reflect delay in making the decision of stopping breastfeeding until weighing benefits and risks.

Cabergoline should not be used in women with pregnancy-induced hypertension, for example, preeclampsia or postpartum hypertension, unless the potential benefit is judged to outweigh the possible risk. ${ }^{16}$ Hypertensive disorders were encountered in 12 patients, with $58.3 \%$ of them having uncontrolled blood pressure for the 24 hours prior to receiving cabergoline. Close monitoring of these patients would be required, especially for blood pressure.

One of the limitations of the study was its retrospective nature that does not provide information about all perspectives of the physicians and patients at the time of prescribing cabergoline. Moreover, unclear and incomplete documentation might reduce the amount of information that could be retrieved. Another limitation is that this DUE assesses the timing of writing the prescription, which might not reflect the exact time of administration, especially with patients who were planned to receive it at discharge as home medication.

Our study described different aspects of clinical practice regarding cabergoline use in lactation inhibition. Future work can be expanded to the evaluation of cabergoline in lactation suppression within the first 2-6 months postpartum, with a focus on patients with live nursing babies.

\section{Conclusion}

This DUE study found that cabergoline use in lactation inhibition was mainly for patients with stillbirth, abortion, and neonatal death. Maternal use of medications for other medical comorbidities requires careful evaluation of breastfeeding benefits and risks before prescribing cabergoline. To further enhance the current prescribing pattern, health care providers need to be informed regarding the appropriate dose, frequency, and safety concerns in patients with uncontrolled hypertension.

\section{Funding}

This work received a grant from the Medical Research Center, Hamad Medical Corporation, Qatar.

\section{Disclosure}

The authors report no conflicts of interest in this work.

\section{References}

1. Stuebe A. The risks of not breastfeeding for mothers and infants. Rev Obstet Gynecol. 2009;2(4):222-231.

2. Mathur NB, Dhingra D. Breastfeeding. Indian J Pediatr. 2014;81(2): 143-149.

3. Tchoffo P. [webpage on the Internet]. Treatment for suppression of lactation: RHL commentary [last revised November 1, 2009]. The WHO Reproductive Health Library. Geneva: World Health Organization. http://apps.who.int/rhl/pregnancy_childbirth/care_after_childbirth/ cd005937_Tchoffopa_com/en/. Accessed April 23, 2015.

4. Oladapo O, Fawole B. Treatments for suppression of lactation. Cochrane Database Syst Rev. 2012;9:CD005937.

5. Nisha S, Uma S, Vineeta S. Role of newer drug cabergoline in lactation suppression as compared to estrogen-androgen combination. J Obstet Gynecol India. 2009;59(2):152-155.

6. Ogbuanu CA, Probst J, Laditka SB, Liu J, Baek J, Glover S. Reasons why women do not initiate breastfeeding: a southeastern state study. Womens Health Issues. 2009;19(4):268-278.

7. Coli M. Lactation after perinatal, neonatal, or infant loss. Clin Lactation. 2012;3(3):94-100.

8. Spitz M, Lee C, Peterson B. Treatment for lactation suppression: little progress in one hundred years. Am J Obstet Gynecol. 1998;179(6 pt 1): $1485-1490$

9. Webster JA. Comparative review of the tolerability profiles of dopamine agonists in the treatment of hyperprolactinaemia and inhibition of lactation. Drug Safety. 1996;14(4):228-238.

10. European Multicentre Study Group for Cabergoline in Lactation Inhibition. Single dose cabergoline versus bromocriptine in inhibition of puerperal lactation: randomised, double blind, multicentre study. $B M J$. 1991;302(6789):1367-1371.

11. Melis B, Gambacciani M, Paoletti M, et al. Dose-related prolactin inhibitory effect of the new long-acting dopamine receptor agonist cabergoline in normal cycling, puerperal, and hyperprolactinemic women. J Clin Endocrinol Metabol. 1987;65(3):541-545.

12. Melis B, Mais V, Paoletti M, Beneventi F, Gambacciani M, Fioretti P. Prevention of puerperal lactation by a single oral administration of the new prolactin-inhibiting drug, cabergoline. Obstet Gynecol. 1988;71(3 pt 1): 311-314.

13. Caballero-Gordo A, Lopez-Nazareno N, Calderay M, Caballero JL, Mancheño E, Sghedoni D. Oral Cabergoline. Single-dose inhibition of puerperal lactation. J Reprod Med. 1991;36(10):717-721.

14. Bravo-Topete G, Mendoza-Hernández F, Cejudo-Alvarez J, BrionesGarduño C. Cabergoline for inhibition of lactation. Cir Cir. 2004; 72(1):5-9.

15. Briggs GG, Freeman R, Yaffe S. Drugs in Pregnancy and Lactation: A Reference Guide to Fetal and Neonatal Risk. Philadelphia, PA: Lippincott Williams \& Wilkins; 2011.

16. Dostinex: Summary of Product Characteristics [webpage on the Internet]. Medicines Compendium UK. Available from: http://www. medicines.org.uk/emc/medicine/10003/spc. Accessed May 11, 2013.

17. World Health Organization (WHO). Drug and Therapeutic Committee: A Practical Guide To Drug Use Evaluation (Drug Utilization Review) Geneva: World Health Organization; 2003:155.

18. Centers for Disease Control and Prevention (CDC) [webpage on the Internet]. Breastfeeding. [cited Mar 28, 2015]. Available from: http:// www.cdc.gov/breastfeeding/disease/. Accessed April 23, 2015. 
19. Section on Breastfeeding. Breastfeeding and the use of human milk: policy statement. Pediatrics. 2012;129:e827-e841.

20. Drugs and Lactation Database (LactMed) [webpage on the Internet]. US National Library of Medicine. Available from: http://toxnet.nlm. nih.gov/cgi-bin/sis/htmlgen?LACTMED. Accessed March 5, 2015.

21. NICE. Hypertension in Pregnancy: The Management of Hypertensive Disorders during Pregnancy. NICE Clinical Guideline 107. London: NICE; 2011.
22. Benson AB, Haith MM. Social and Emotional Development in Infancy and Early Childhood. 1st ed. Waltham, MA: Academic Press; 2009.

23. King TL, Brucker MC, Kriebs JM, Fahey JO. Varney's Midwifery. 5th ed. Burlington, MA: Jones \& Bartlett Learning; 2013.

\section{Publish your work in this journal}

Therapeutics and Clinical Risk Management is an international, peerreviewed journal of clinical therapeutics and risk management, focusing on concise rapid reporting of clinical studies in all therapeutic areas, outcomes, safety, and programs for the effective, safe, and sustained use of medicines. This journal is indexed on PubMed Central, CAS,
EMBase, Scopus and the Elsevier Bibliographic databases. The manuscript management system is completely online and includes a very quick and fair peer-review system, which is all easy to use. Visit $\mathrm{http}: / / \mathrm{www}$.dovepress.com/testimonials.php to read real quotes from published authors.

Submit your manuscript here: http://www.dovepress.com/therapeutics-and-clinical-risk-management-journal 